\title{
Phacotrabeculectomy versus Trabeculectomy with Small Incision Cataract Extraction in Eyes Presenting with Cataract and Glaucoma Mohammed IA ${ }^{1}$, Abdelhameed $\mathrm{MH}^{2}$ and Eassa IM ${ }^{3}$ \\ ${ }^{1}$ Ophthalmology department -Faculty of medicine, Al -Azhar University (Cairo), ${ }^{2}$ Ophthalmology department- Faculty of medicine, Al -Azhar University (Damietta) and ${ }^{3}$ Ophthalmology department- Faculty of medicine, Al -Azhar University (Damietta)
}

*Corresponding Author: Mostafa Ismail Eassa, Phone No.: (+20) 01123320632, E-mail: mohamedmoustafa8787@gmail.com

\begin{abstract}
Background: The association of glaucoma with cataract has been more frequent because of increase in life expectancy and the increased risk of cataract development in patient with glaucoma.

Aim of the work: was to compare the outcome of phacotrabeculectomy versus subscleral trabeculectomy with small incision cataract extraction in patients with cataract and primary glaucoma.

Patients and Methods: This prospective study included a total of 20 eyes of 19 patients with visually significant cataract and coexisting primary glaucoma. Patients were categorized randomly in two groups: group A who underwent phacotrabeculectomy and group B who underwent trabeculectomy with small incision cataract extraction from the same trab.

Results: Statistically significant improvement was detected in postoperative BCVA and IOP. Preoperative BCVA ranged from 0.02 to 0.25 with the mean $\pm \mathrm{SD}$ of $0.15 \pm(0.07)$ in phacotrabeculectomy group (group A) while in small incision trabeculectomy group (group B) preoperative BCVA ranged from 0.01 to 0.25 with the mean \pm SD of $0.11 \pm(0.1)$. Preoperative IOP ranged from $30-35 \mathrm{mmHg}$ with mean $\pm \mathrm{SD}$ of $31.28 \pm(1.25)$ in phacotrabeculectomy group while in small incision trabeculectomy group preoperative IOP ranged from $30-36 \mathrm{mmHg}$ with mean $\pm \mathrm{SD}$ of $31.14 \pm(1.34)$.

Conclusions: It could be concluded that there is significant improvement in the BCVA and IOP control after combined procedure for management of coexistent cataract and glaucoma. This improvement is statistically significant. There was no statistically significant difference in the final visual acuity, IOP control and postoperative complication rate between phacotrabeculectomy and small incision trabeculectomy.
\end{abstract}

Keywords: Cataract, phacotrabeculectomy, small incision, glaucoma.

\section{INTRODUCTION}

Cataracts are the leading cause of blindness worldwide, not only a medical problem but also a social problem that takes into account population aging (1). Congenital cataracts may be dementia, shock, complicated because of uvietis, metabolism as diabetic cataracts and toxicity ${ }^{(2)}$.

Glaucoma is an annoying eye disease that destroys the optic nerve and can lead to irreversible gradual loss of vision and blindness at the end. Glaucoma may be either an open angle representing $90 \%$ of all narrow-angle glaucoma or angle-closure glaucoma. Other types are natural stress glaucoma, congenital and secondary glaucoma such as glaucoma (3). There is no cure for glaucoma as yet, and vision loss is irreversible. However medication or surgery can slow-down any further vision loss. Therefore early detection is essential to limiting visual impairment and preventing the progression towards several visual handicap or blindness ${ }^{(4)}$.

The association of glaucoma with cataract has been more frequent because of increase in life expectancy and the increased risk of cataract development in patient with glaucoma. Moreover, the presence of cataract can affect the ability to assess glaucoma progression, and cataract extraction affects intra ocular pressure as well as effectiveness of glaucoma surgery ${ }^{(5)}$.

Combined procedure considered in visually significant cataract and one of the following situations: Drug induced side effects, IOP control on maximum tolerated therapy but advanced glaucomatous optic atrophy or uncontrolled glaucoma on maximum medications and there is need to restore vision. Some studies have shown that postoperative complication rates and IOP were lower when cataract surgery was combined with trabeculectomy ${ }^{(\mathbf{6})}$.

Manual small-incision cataract surgery with trabeculectomy also is an acceptable option in the surgical management of combined cataract and glaucoma. There are some benefits from small incision cataract surgery in the form of less manipulation, less trauma, less side effects of ultrasound and suitable in certain conditions like small pupil and hard cataract ${ }^{(7)}$.

The aim of the current work was to compare the outcome of phacotrabeculectomy versus subscleral trabeculectomy with small incision cataract extraction in patients with cataract and primary glaucoma.

\section{PATIENTS AND METHODS}

This prospective study included a total of 20 eyes of 19 patients with visually significant cataract and coexisting primary glaucoma attending at the 
outpatient clinic of Al-Azhar University Hospitals. Approval of the ethical Board of Al-Azhar University and a written informed consent from all the subjects were obtained. This study was conducted between January 2018 to February 2019.

Patients were categorized randomly in two groups: group A who underwent phacotrabeculectomy and group B who underwent trabeculectomy with small incision cataract extraction from the same trab.

Inclusion Criteria: Patient with visually significant cataract and coexisting primary glaucoma.

Exclusion Criteria: Patients who refuse to participate or continue to participate, secondary glaucoma (pseudoexfoliation, pigmentaryglaucoma, neovascular.glaucoma and inflammatory glaucoma, previous ocular trauma or surgery and other ocular diseases as retinal detachment.

\section{The included patients were subjected to:}

1. History taking: onset, course and duration of diminution of vision, history of ocular trauma, ocular surgery, systemic disorder and drug intake.

2. General examination: review for systemic diseases as hypertension, bleeding tendency and renal impairment.

3. Laboratory investigation: Basic laboratory investigations including fasting and 2 hour postprandial blood glucose, coagulation profile, liver and kidney function tests, to exclude ineligible cases.

4. Preoperative ophthalmological examination: Best corrected visual acuity (BCVA), were evaluated by landot C optotype using Snellen`s chart, pupil reaction, refraction using Nidek automated refractometer.

- Slit lamp examination to assess corneal clarity, depth of anterior chamber, state of pupil dilatation, lens morphology, and any pathological finding.

- Intraocular pressure (IOP) by Goldman Applanation tonometer.

- Fundus examination: slit lamp biomicroscopy using non-contact Volk 90 Diopter lens.

- Assessment of ocular motility in all direction of gaze.

- Examination of ocular adnexa.

5. Preoperative medication monitoring:

- Miotcs stopped two weeks before surgery as they predispose to bleeding, carbonic anhydrase inhibitors stopped at least 6 hours before surgery to avoid suppression of aqueous flow in postoperative period. B blockers should be stopped for the same cause.

- IOP should not more than $30 \mathrm{mmHg}$ before operation.

- Topical NSAIDS are given three days before surgery and topical antibiotics (Moxifloxacin) 1week before surgery.

6. Preoperative investigations:

- Calculation of IOL power and axial length by Sonomed Biometry model 5500.

- Optical coherence tomography (OCT) by Topcon 3D 2000 OCT.when ever possible to analyses the optic nerve head and macula.
- Visual field examination using a Humphrey Field Analyzer whenever possible.

Ultra sound to assess the posterior segment especially in dense cataract.

- All patients had informed written consent.

7. Operative details:

- Group A had undergone phacotrabeculectomy through these steps:

(1). local peribulbar block. (2) Superior peritomy (limbal based flap) is performed to expose bare sclera. Gentle cautery is performed as needed. (3) A partial-thickness scleral flap $t$ (triangular flap)(4) A keratome is used to enter the anterior chamber.(5) Two side port with MVR blade At 2,8 o'clock.(6) Phacoemulsification is performed in the usual manner.(Stop and shop).(7) Intraocular lens implantation.(8) Removal of viscoelastic solution. (9) with a sharp blade or MVR knife, and a block of tissue $3.5 \times 1 \mathrm{~mm}$ is cut with Vanna's scissors. This part should involve scleral spur, canal of Schlemm, trabecular meshwork and peripheral cornea with peripheral iridectomy. (10) The scleral flap is closed using interrupted sutures by Nylon 10/0. (11)conjunctiva is closed by Vicryl $8 / 0$

- Group B under SICE with trabeculectomy through these steps (1). local peribulbar block. (2) Superior peritomy (limbal based flap) is performed to expose bare sclera. Gentle cautery is performed as needed.(3). A partial-thickness scleral flap $t$ (triangular flap) (4) A keratome is used to enter the anterior chamber. (5) Formation of the anterior chamber by viscoelastic material anterior continuous circular curvilinear capsulorrhexis performed under viscoelastic material. (6) Multiple small hydrodissections facilitate prolapse of the nucleus into the anterior chamber.(7) The nucleus is delivered by visco- expression technique (viscoelastic injected beyond the inferior margin of the nucleus) while the posterior lip of the tunnel is gently depressed till delivery of the nucleus.(8)Residual cortex aspiration and IOL implantation.(9) with a sharp blade or MVR knife, and a block of tissue $3.5 \times 1 \mathrm{~mm}$ is cut with Vanna's scissors .this part should involve scleral spur, canal of Schlemm, trabecular meshwork and peripheral cornea with peripheral iridectomy.(10) The scleral flap is closed using interrupted suture using Nylon 10/0.(11). conjunctiva is closed using Vicryl 8/0.

\section{Post-operative follow-up:}

- $\quad$ The patients reviewed at 1 st day

postoperative then at 3 visit(1week, 4weeks and 12 weeks postoperative) At each visit intra ocular pressure assessment, BCVA, slit-lamp examination. Anterior chamber, bleb examination, intra ocular lens and wound assessment.

\section{Statistical analysis}

- The collected data were organized, tabulated and statistically analyzed using statistical package for 
social sciences (SPSS) version 19 (SPSS Inc, Chicago, USA). For qualitative data, frequency and percent distributions were calculated. For quantitative data, mean and standard deviation (SD) were calculated. For comparison between two groups, the independent samples $(t)$ test was used. For all tests $\mathrm{p}$ value $<0.05$ were considered significant. For all tests $\mathrm{p}$ value $>0.05$ were considered insignificant.

Table (1): Demographic data of the studied cases

\begin{tabular}{|l|l|c|c|c|c|}
\hline \multicolumn{2}{|l|}{} & Group I & Group II & T test & P value \\
\hline \multicolumn{2}{|l|}{$\begin{array}{l}\text { Age (mean } \\
\text { Range }\end{array}$} & $\begin{array}{c}64.0 \pm 5.35 \\
(52-67)\end{array}$ & $\begin{array}{c}68.5 \pm 4.83 \\
(62-75)\end{array}$ & 1.68 & 0.12 \\
\hline \multirow{2}{*}{ Sex } & Male & $8(80.0 \%)$ & $6(60.0 \%)$ & 0.97 & 0.33 \\
\cline { 2 - 4 } & Female & $2(20.0 \%)$ & $4(40.0 \%)$ & & \\
\hline \multirow{2}{*}{$\begin{array}{l}\text { Operative } \\
\text { eye }\end{array}$} & Right & $6(60.0 \%)$ & $6(60.0 \%)$ & & \\
\cline { 2 - 4 } $\begin{array}{l}\text { Systemic } \\
\text { disease }\end{array}$ & Left & $4(40.0 \%)$ & $4(40.0 \%)$ & & \\
\cline { 2 - 4 } & HTN & $10(100.0 \%)$ & $3(30.0 \%)$ & & \\
\cline { 2 - 4 } & HCV & $2(20.0 \%)$ & $5(50.0 \%)$ & & \\
\cline { 2 - 4 } & IHD & $1(10.0 \%)$ & $1(10.0 \%)$ & & \\
\cline { 2 - 4 } & IDDM & $0(0.0 \%)$ & $1(10.0 \%)$ & & \\
\hline
\end{tabular}

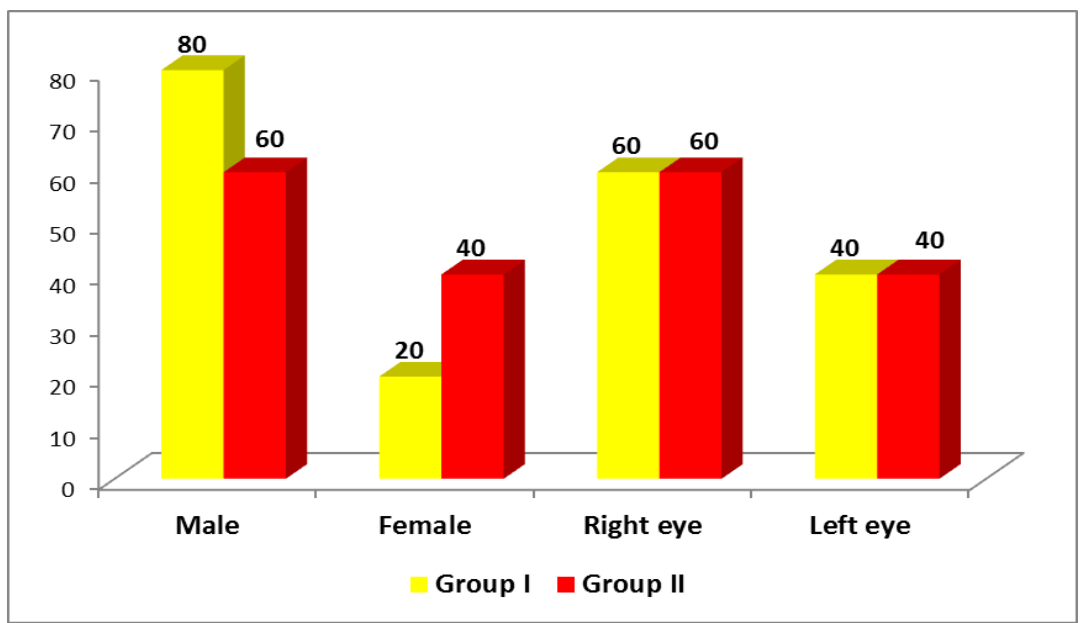

Figure (1): Comparison between studied cases regarding sex distribution and operating eye.

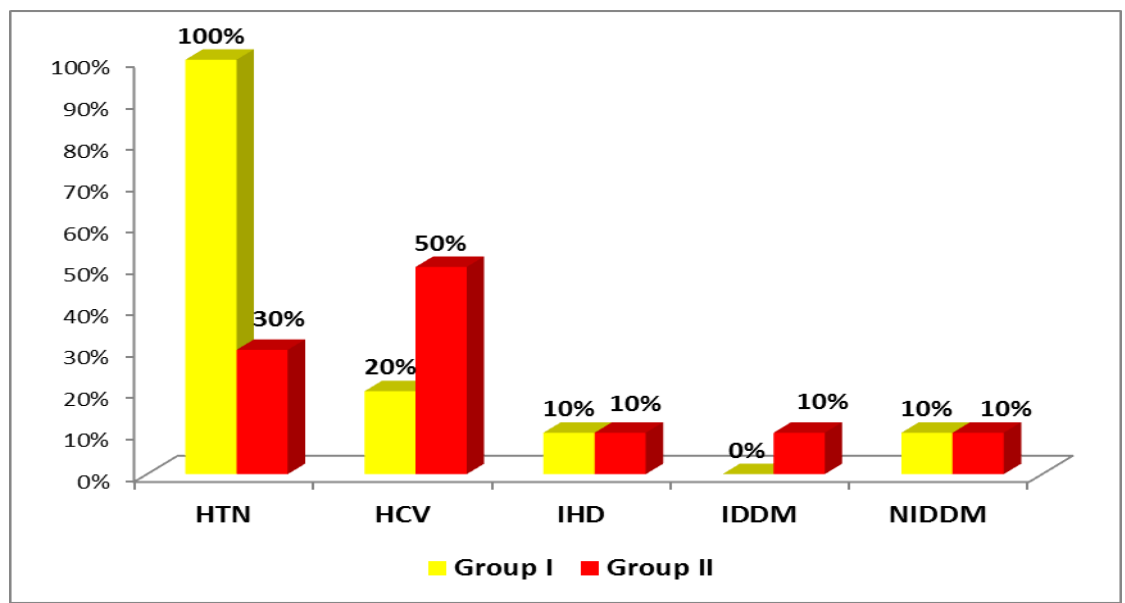

Figure (2): Comparison between studied cases regarding sex distribution and operating eye 
Table (2): Comparison between studied cases regarding type of cataract and fundus examinations

\begin{tabular}{|l|c|c|c|}
\hline \multicolumn{2}{|l|}{ Types of cataract } & Group I & Group II \\
& PSC & $4(40.0 \%)$ & $1(10.0 \%)$ \\
& Nuclear & $1(10.0 \%)$ & $0(0.0 \%)$ \\
\hline Fundus (C/D ratio) (mean \pm SD) & $5(50.0 \%)$ & $9(90.0 \%)$ \\
Range & $\mathbf{. 6 8}$ & .67 \\
& $\mathbf{( . 6 - . 8 )}$ & $\mathbf{( . 5 - . 8 )}$ \\
\hline
\end{tabular}

Table (3): Comparison between studied cases regarding axial length, operating time and IOL (mean \pm SD)

\begin{tabular}{|l|c|c|c|c|}
\hline & Group I & Group II & T test & p-value \\
\hline Axial length & $22.73 \pm 0.52$ & $22.8 \pm 0.74$ & 0.21 & 0.84 \\
Range & $(22-23.2)$ & $(21.6-23.6)$ & & \\
\hline Operating time & $29.0 \pm 1.01$ & $32.71 \pm 2.04$ & 1.62 & 0.13 \\
Range & $(27-34)$ & $(25-40)$ & & \\
\hline IOL & $21.14 \pm 0.69$ & $21.43 \pm 0.53$ & 0.86 & 0.4 \\
Range & $(20-22)$ & $(21-22)$ & & \\
\hline
\end{tabular}

Statistically significant improvement was detected in postoperative BCVA and IOP. As regard BCVA Preoperative BCVA ranged from 0.02 to 0.25 with the mean $\pm \mathrm{SD}$ of $0.15 \pm(0.07)$ in phacotrabeculectomy group (group A) while in small incision trabeculectomy group (group B) preoperative BCVA ranged from 0.01 to 0.25 with the mean \pm SD of $0.11 \pm(0.1)$. At the $4^{\text {th }}$ week postoperative BCVA ranged from 0.1 to 0.5 with the mean \pm SD of 0.31 $\pm(0.14)$ in phacotrabeculectomy group while in small incision trabeculectomy group at the $4^{\text {st }}$ week postoperative BCVA ranged from 0.1 to 0.5 with the mean \pm SD of $0.27 \pm(0.16)$.at the $12^{\text {th }}$ week postoperative BCVA ranged from 0.15 to 0.5 with the mean \pm SD of $0.36 \pm(0.14)$ in phacotrabeculectomy group while in small incision trabeculectomy group at the $12^{\text {st }}$ week postoperative BCVA ranged from 0.15 to 0.6 with the mean \pm SD of $0.29 \pm(0.19)$.

Table (4): Comparison between studied cases regarding pre-operative and post-operative BCVA (mean \pm SD)

\begin{tabular}{|c|c|c|c|c|}
\hline & Group & Group I & T tes & p-valu \\
\hline Preoperative & $0.15 \pm 0.07$ & $0.11 \pm 0.1$ & 0.88 & 0.39 \\
Range & $(0.02-0.25)$ & $(0.01-0.25)$ & & \\
\hline $\mathbf{1}^{\text {st }}$ week & $0.24 \pm 0.14$ & $0.20 \pm 0.16$ & 0.43 & 0.76 \\
Range & $(0.1-0.5)$ & $(0.05-0.5)$ & & \\
\hline $\mathbf{1}^{\text {st }}$ month & $0.31 \pm 0.14$ & $0.27 \pm 0.16$ & 0.52 & 0.61 \\
Range & $(0.1-0.5)$ & $(0.1-0.5)$ & & \\
\hline 3 $^{\text {rd }}$ month & $0.36 \pm 0.14$ & $0.29 \pm 0.19$ & 0.73 & 0.44 \\
Range & $(0.15-0.5)$ & $(0.15-0.6)$ & & \\
\hline
\end{tabular}

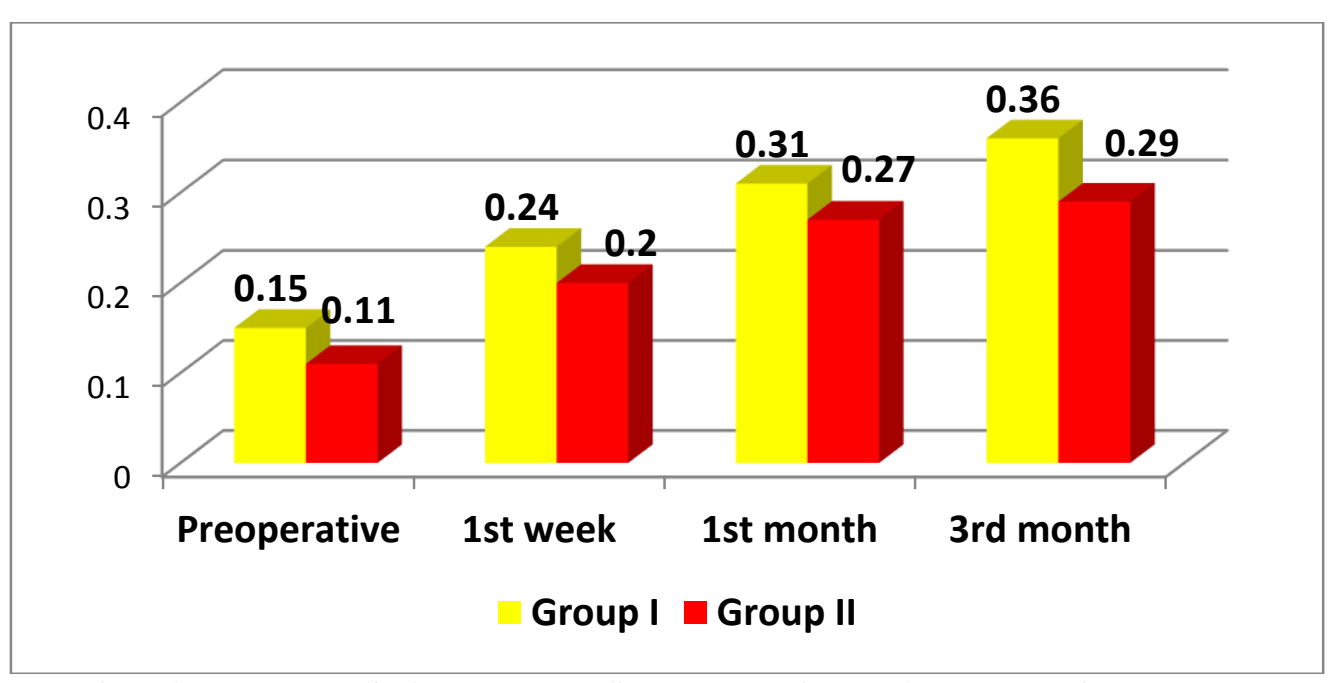

Figure (3): Comparison between studied cases regarding preperative and postoperative BCVA. 
As regard IOP preoperative IOP ranged from 30$35 \mathrm{mmHg}$ with mean $\pm \mathrm{SD}$ of $31.28 \pm$ (1.25) in phacotrabeculectomy group while in small incision trabeculectomy group preoperative IOP ranged from 30 -36 mmHg with mean \pm SD of $31.14 \pm$ (1.34). at the $4^{\text {th }}$ week postoperative IOP ranged from 13-20 with the mean $\pm \mathrm{SD}$ of $15.0 \pm(2.44)$ in phacotrabeculectomy group while in small incision trabeculectomy group at the $4^{\text {st }}$ week postoperative IOP ranged from 14 to 16 with the mean \pm SD of $15.57 \pm(1.39)$.at the $12^{\text {th }}$ week postoperative IOP ranged from 12-20 with the mean \pm SD of $14.71 \pm(2.56)$ in phacotrabeculectomy group while in small incision trabeculectomy group at the $12^{\mathrm{s}}$ week postoperative IOP ranged from 11 to 18 with the mean \pm SD of $14.57 \pm(2.22)$.

Table (5): Comparison between studied cases regarding IOP.

\begin{tabular}{|l|c|c|c|c|}
\hline & Group I & Group II & T test & p-value \\
\hline $\begin{array}{l}\text { Preoperative (1week before } \\
\text { operation } \\
\text { Range }\end{array}$ & $\begin{array}{l}31.28 \pm 1.25 \\
(30-35)\end{array}$ & $\begin{array}{l}31.14 \pm 1.34 \\
(30-36)\end{array}$ & 0.21 & 0.84 \\
\hline $\begin{array}{l}\mathbf{1}^{\text {st }} \text { week postoperative } \\
\text { Range }\end{array}$ & $\begin{array}{c}15.86 \pm 3.07 \\
(12-22)\end{array}$ & $\begin{array}{c}15.43 \pm 2.6 \\
(11-18)\end{array}$ & 0.28 & 0.78 \\
\hline $\begin{array}{l}\mathbf{1}^{\text {st }} \text { month postoperative } \\
\text { Range }\end{array}$ & $\begin{array}{c}15.0 \pm 2.44 \\
(13-20)\end{array}$ & $\begin{array}{c}15.57 \pm 1.39 \\
(14-16)\end{array}$ & 0.54 & 0.6 \\
\hline $\begin{array}{l}\mathbf{3}^{\text {rd }} \text { month postoperative } \\
\text { Range }\end{array}$ & $\begin{array}{c}14.71 \pm 2.56 \\
(12-20)\end{array}$ & $\begin{array}{c}14.57 \pm 2.22 \\
(11-18)\end{array}$ & 0.11 & 0.91 \\
\hline
\end{tabular}

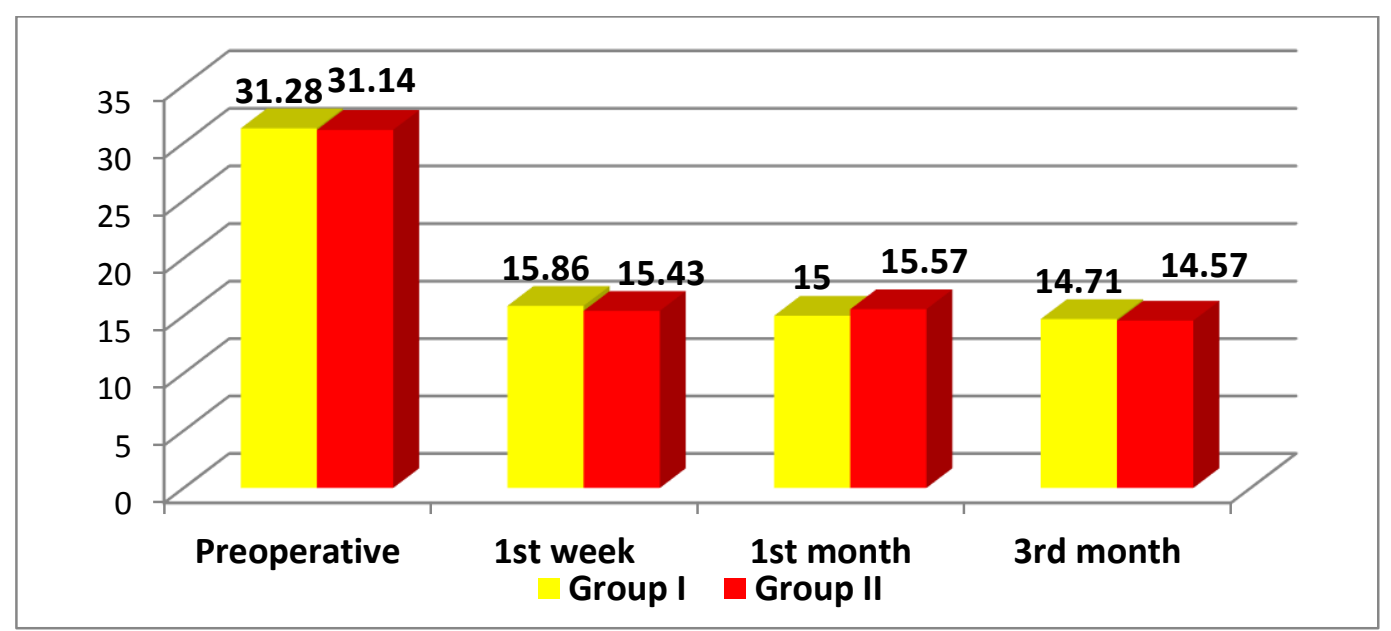

Figure (4): Comparison between studied cases regarding IOP.

In the present study in the $1^{\text {st }}$ day post-operative, there were $20.0 \%$ of cases with mild edema in cornea in group I and $40.0 \%$ in group II. There were $20.0 \%$ with shallow anterior chamber grade I and $10.0 \%$ with grade II in group I but in group II there was $20.0 \%$ with grade I only. There were $20.0 \%$ of cases with leaky wound. There were $70.0 \%$ of cases with flat diffuse bleb in both groups and $30.0 \%$ of cases with well formed bleb.

Table (6): Comparison between studied group regarding $1^{\text {st }}$ day post-operative examination.

\begin{tabular}{|c|l|r|c|}
\hline \multirow{2}{*}{$\begin{array}{c}\text { Corneal } \\
\text { assessment }\end{array}$} & \multicolumn{1}{|c|}{ Clear } & Group I & \multicolumn{1}{c|}{ Group II } \\
\cline { 2 - 4 } $\begin{array}{c}\text { Anterior } \\
\text { chamber }\end{array}$ & Mild edema & $8(80.0 \%)$ & $6(60.0 \%)$ \\
\cline { 2 - 4 } & Well formed & $2(20.0 \%)$ & $4(40.0 \%)$ \\
\cline { 2 - 4 } & Shallow AC grade I & $7(70.0 \%)$ & $8(80.0 \%)$ \\
\cline { 2 - 4 } Bleb & Shallow AC grade II & $2(20.0 \%)$ & $2(20.0 \%)$ \\
\cline { 2 - 4 } & Flat diffuse & $1(10.0 \%)$ & $0(0.0 \%)$ \\
\cline { 2 - 4 } & Well formed & $7(70.0 \%)$ & $7(70.0 \%)$ \\
\hline \multirow{2}{*}{ Wound } & Sealed & $3(30.0 \%)$ & $3(30.0 \%)$ \\
\cline { 2 - 4 } & Leaky wound & $2(20.0 \%)$ & $10(100.0 \%)$ \\
\hline \multirow{2}{*}{ IOL } & In-place & $10(100.0 \%)$ & $10(100.0 \%)$ \\
\hline
\end{tabular}




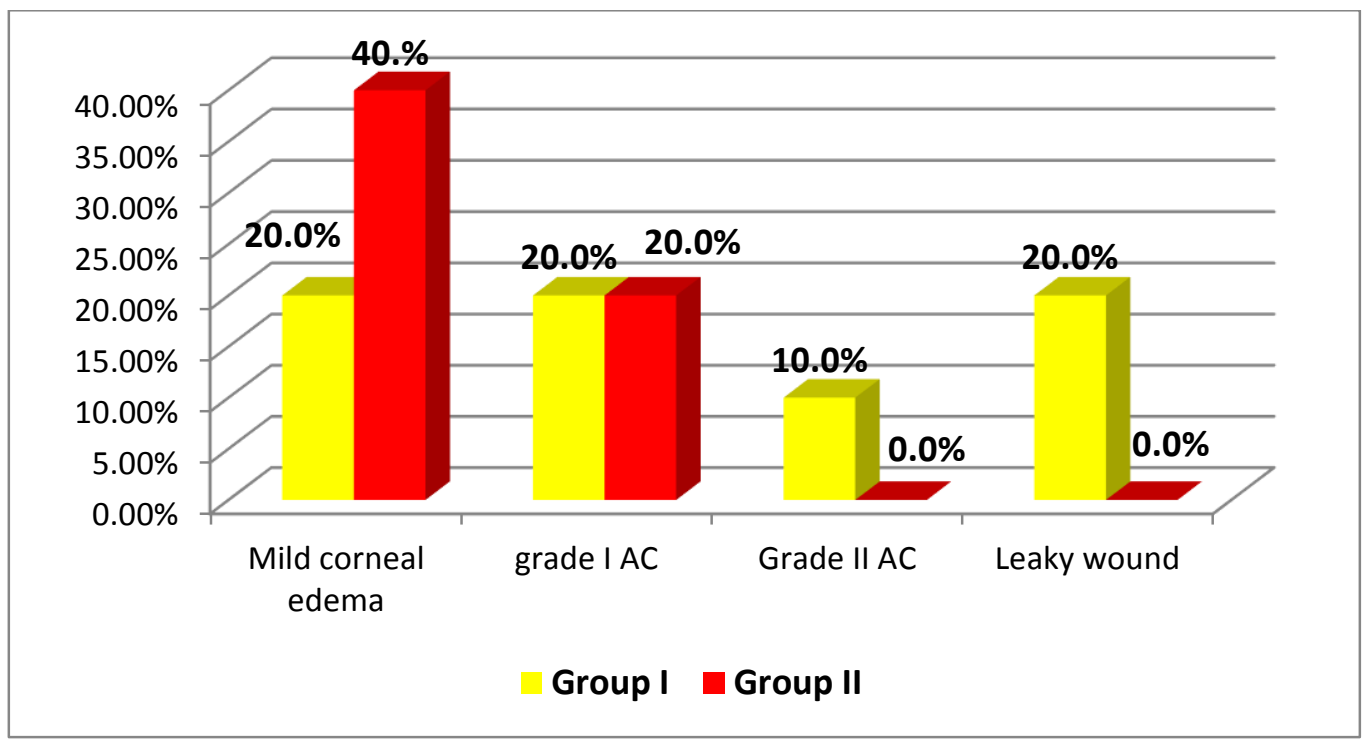

Figure (5): Comparison between studied group regarding $1^{\text {st }}$ day post-operative examination.

In the present study in the $1^{\text {st }}$ week post-operative, there were $20.0 \%$ of cases with mild corneal edema in group I. There were $20.0 \%$ with irritant wound stitch in group I.

Table (7): Comparison between studied group regarding postoperative $1^{\text {st }}$ week examination.

\begin{tabular}{|c|c|c|c|c|c|}
\hline & & Group I & Group II & T test & P value \\
\hline \multirow{2}{*}{$\begin{array}{l}\text { Corneal } \\
\text { assessment }\end{array}$} & Clear & $8(80.0 \%)$ & $10(100.0 \%)$ & \multirow[t]{2}{*}{1.49} & \multirow[t]{2}{*}{0.14} \\
\hline & Mild edema & $2(20.0 \%)$ & $0(0.0 \%)$ & & \\
\hline \multirow[t]{2}{*}{ Bleb } & Flat diffuse & $7(70.0 \%)$ & $7(70.0 \%)$ & & \\
\hline & Well formed & $3(30.0 \%)$ & $3(30.0 \%)$ & & \\
\hline \multirow[t]{2}{*}{ Wound } & Sealed & $8(80.0 \%)$ & $10(100.0 \%)$ & \multirow[t]{2}{*}{1.49} & \multirow[t]{2}{*}{0.14} \\
\hline & Irritant stitch & $2(20.0 \%)$ & $0(0.0 \%)$ & & \\
\hline IOL & In-place & $10(100.0 \%)$ & $10(100.0 \%)$ & & \\
\hline
\end{tabular}

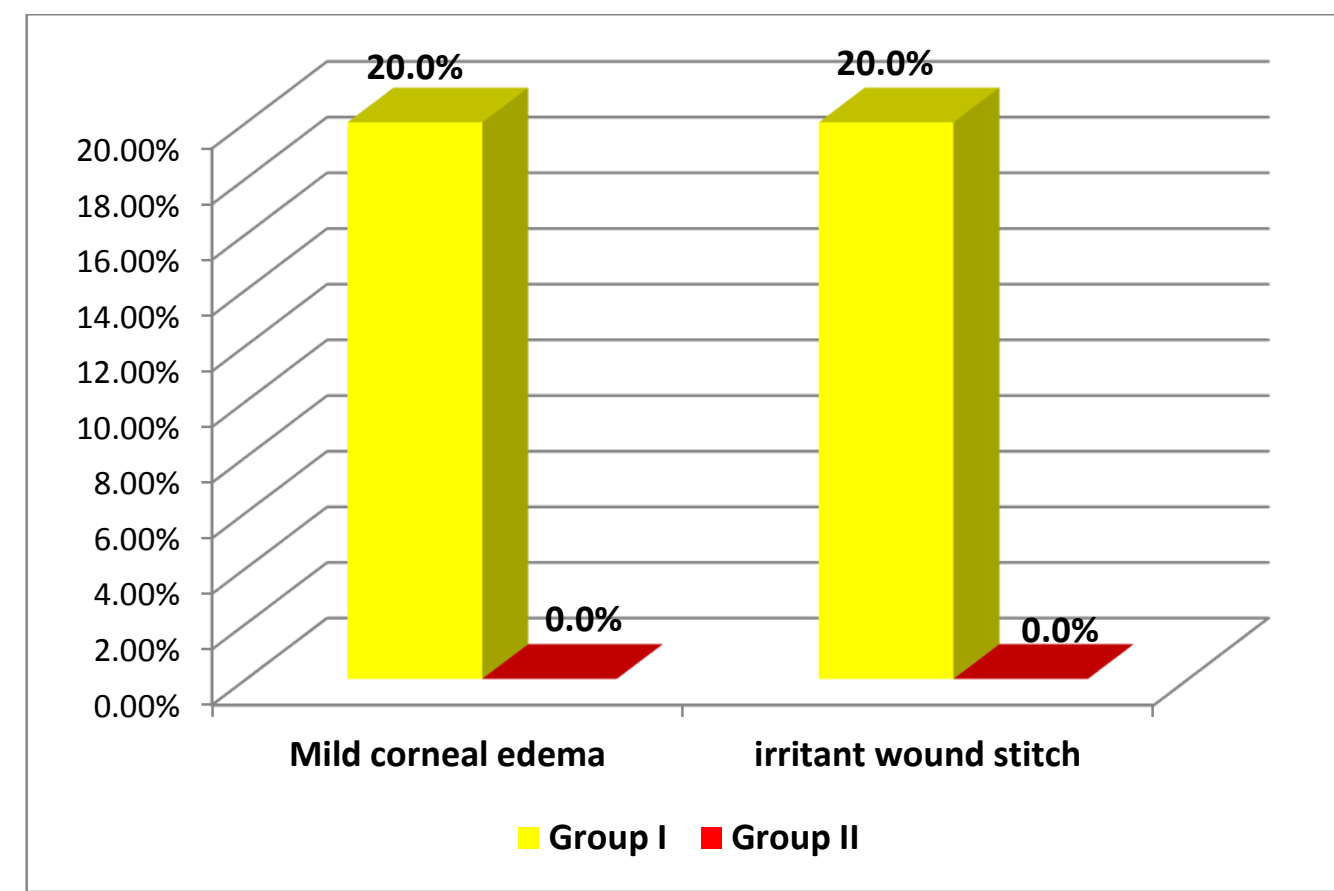

Figure (6): Comparison between studied group regarding 1 week post-operative examination.

In the present study in the $3^{\text {rd }}$ month post-operative, there were no cases suffered from corneal edema and irritant stitch wound in group I and II.

Table (8): Comparison between studied group regarding 3 months postoperative examination. 


\begin{tabular}{|c|c|c|c|}
\hline & & Group I & Group II \\
\hline \multirow{2}{*}{$\begin{array}{l}\text { Corneal } \\
\text { assessment }\end{array}$} & Clear & $10(100.0 \%)$ & $10(100.0 \%)$ \\
\hline & Mild edema & $0(0.0 \%)$ & $0(0.0 \%)$ \\
\hline \multirow[t]{2}{*}{ Bleb } & Flat diffuse & $7(70.0 \%)$ & $7(70.0 \%)$ \\
\hline & Well formed & $3(30.0 \%)$ & $3(30.0 \%)$ \\
\hline \multirow[t]{2}{*}{ Wound } & Sealed & $10(100.0 \%)$ & $10(100.0 \%)$ \\
\hline & Irritant stitch & $0(0.0 \%)$ & $0(0.0 \%)$ \\
\hline IOL & In-place & $10(100.0 \%)$ & $10(100.0 \%)$ \\
\hline
\end{tabular}

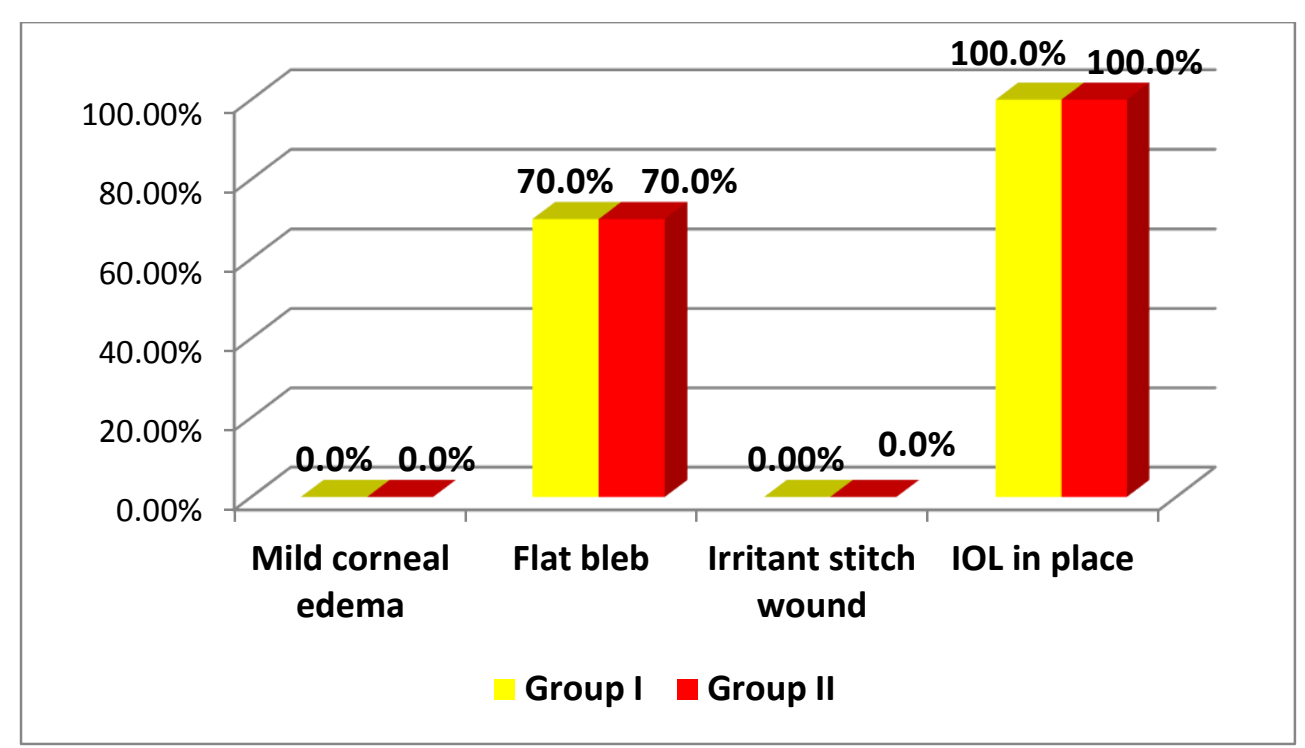

Figure (7): Comparison between studied group regarding 3 months post-operative examination.

\section{DISCUSSION}

Developments in cataract extraction and the improvements in trabeculectomy and non-penetrating filtering surgery and implant drainage devices have favored the trend for doing a combined surgery ${ }^{(8)}$.

The goal of treatment in a glaucoma patient with cataract, is to achieve an adequate long-term control of intraocular pressure (IOP), avoid postoperative IOP spikes which are deleterious to the health of the optic nerve head, obtain an optimal visual rehabilitation and improve the quality of life of the patient. Cataract surgery alone has significant effects on the intraocular pressure. Following an early rise in the intraocular pressure, the IOP tends to fall in the long run. Although significant, the magnitude of the change is small, averaging around 2-4 $\mathrm{mm} \mathrm{Hg}$ and one cannot depend on this as a means of lowering the IOP (9).

Also, both the diseases are controlled in a single sitting, thus it reduces the need for glaucoma medications and frequent follow-ups ${ }^{(\mathbf{1 0})}$.

The advent of small incision cataract surgery both by phacoemulsification or manual small incision along with trabeculectomy has improved the IOP control outcome, other advantages include less induced astigmatism, early visual rehabilitation, reduced stimuli to wound healing, inflammation and postoperative bleb scarring and thus improving longterm filtration ${ }^{(\mathbf{1 1})}$.
Singh et al. ${ }^{(12)}$ published the following results during follow up of thirty consecutive patients who underwent combined surgery performed by the same surgeon were prospectively evaluated for a minimum period of 12 months. 19 women and 11 men aged 4085 years, Fifteen patients underwent single site phacotrabeculectomy, and the remaining 15 patients underwent single site phacofracture trabeculectomy at Guru Nanak Eye Hospital, New Delhi. As regard the Intraocular pressure control the preoperative mean IOP in both phacotrabeculectomy and phacofracture trabeculectomy groups was $29 \pm 3$ $\mathrm{mm} \mathrm{Hg}$. The reduction in mean IOP at the end of 3 months was $46 \%$ in the phacotrabeculectomy group and $44 \%$ in phacofracture trabeculectomy group. At the 12 months follow-up the percentage reduction was similar to that seen at 3 months. The intergroup difference was not statistically significant at any time. No case developed ocular hypotony $(<4 \mathrm{~mm} \mathrm{Hg})$ at any time during the follow-up period. The complete success rate (IOP $<21 \mathrm{~mm} \mathrm{Hg}$ ) without additional antiglaucoma medications was $100 \%$ in both the groups at the interim follow-up of 3 months and at the last follow-up of 12 months.

In the phacotrabeculectomy group in the current study, most of the patients had flat or absent bleb (Grade 1) except two patients who had elevated engorged conjunctiva (Grade II bleb), whereas in the phacofracture group, all the patients had a Grade I bleb. 
Phacotrabeculectomy versus Trabeculectomy...

As regard visual acuity the range of preoperative visual acuity in log minimum angle of resolution equivalent varied from 0.5 to 3 in both groups and the mean visual acuity was 2.14 in phacotrabeculectomy group and 2.21 in phacofracture group. Postoperatively $53 \%$ patients in phacotrabeculectomy group and $60 \%$ patients in phacofracture group had final corrected visual acuity of 0.3 or better.

There was no anterior chamber inflammation in $67 \%$ patients of phacotrabeculectomy group, whereas in the phacofracture group only $33 \%$ cases were free from the inflammatory reaction. The reaction resolved completely by day 14 in both the groups.

Our results suggest that there is no significant difference in visual acuity and IOP control between phacotrabeculectomy and phacofracture trabeculectomy.

As regard IOP The final percentage reduction in mean IOP was $52.9 \%$ in phacoemulsification with trabeculectomy group and $53.2 \%$ in small incision trabeculectomy group after 3 months in comparison to preoperative IOP .No postoperative hypotony (IOP $<6$ $\mathrm{mm} \mathrm{Hg}$ ) or IOP spikes were noted. The complete success rate (IOP $<21 \mathrm{mmHg}$ ) without additional antiglaucoma medications was $100 \%$ for both the groups. As regard visual acuity The range of preoperative visual acuity in phacotrabeculectomy group on Decimal varied from $(0.02: 0.25)$ and the mean preoperative BCVA was 0.15 while in small incision trabeculectomy group the range was $(0.1$ : $0.25)$ and the mean visual acuity was 0.1 . Postoperatively ( 3 months) the range of BCVA (.15: $.5)$ and the mean BCVA .3 in phacotrabeculectomy group while in Small incision group the range of BCVA (.15 : .6) and the mean BCVA 0.29

As regard postoperative examination there were 3 cases in each group has formed bleb and 7 cases has flat diffuse bleb. No cases show postoperative inflammation or IOP more than $20^{(\mathbf{1 3})}$.

Choy ${ }^{(13)}$ published the following results during his comparative study between phacotrabeculectomy and trabeculectomy alone in Chinese glaucoma patients. He compare the surgical outcomes up to 3 months of 38 consecutive Chinese glaucoma patients who underwent trabeculectomy $(n=18)$ or phacotrabeculectomy $(n=20)$.

Baseline age, visual acuity, and intraocular pressure were comparable. Intraocular pressure from post-operative 1 day to 3 months were similar between 2 groups. Complete success was achieved in $65 \%$ of phacotrabeculectomy, and $66.7 \%$ of trabeculectomy cases; while failure occurred in $16.7 \%$ of phacotrabeculectomy, and $10 \%$ of trabeculectomy cases at 3 months.

Phacotrabeculectomy group consistently showed better improvement in visual acuity. Diffuse blebs occurred in $65 \%$ of phacotrabeculectomy and
$83 \%$ of trabeculectomy eyes; and flat blebs in $35 \%$ of phacotrabeculectomy, but none after trabeculectomy.

There was more hypotony (5\% vs 0 ) after phacotrabeculectomy. phacotrabeculectomy To conclude, demonstrated comparable intraocular pressure control up to 3months post-operatively. However, phacotrabeculectomy patients had better visual acuity improvement. Nonetheless, more diffuse bleb and less hypotony were present following trabeculectomy ${ }^{(14)}$.

Khandelwal et al. ${ }^{(14)}$ published the following results in their retrospective study of 105 cases to compare the efficacy of single site phacotrabeculectomy versus small incision trabeculectomy using the sandwich technique in primary glaucoma coexistent with cataract.Safe surgery system trabeculectomy with diffuse and posterior application of mitomycin $\mathrm{C}$ was performed in all cases. trabeculectomy was combined with MSICS (MSICStrab) in 72 case and combined with phacoemulsification (phaco-trab) in 33 case. 53 MSICS-trab and 22 phacotrab were included in the analysis and the remaining cases were excluded from the study.

There were 25 POAG and 50 PACG patients in whom first operated eye was considered for analysis. The mean follow-up was 13.73 months (range 12-18 months). surgical success of safe surgery system trabeculectomy was achieved in 69 (92\%) out of the 75 cases, and preset target IOP (without or with medication) was achieved in $58(77.3 \%)$ cases. The target IOP achieved was $38(71.7 \%)$ in MSICS-trab, and it was $20(90.9 \%)$ in phaco-trab cases.

At the last follow-up, a significant reduction in the mean IOP from baseline was observed in all the combined cases from postoperative day 1 , irrespective of the type of cataract surgery. The mean IOP was reduced from 26.5 (SD 5) $\mathrm{mmHg}$ to 14.9 (SD 3) $\mathrm{mmHg}$ in the MSICS-trab cases while from 25.2 (SD 5) $\mathrm{mmHg}$ to 14.6 (SD 3) $\mathrm{mmHg}$ in the phaco-trab cases.

The visual acuity improvement was noted in 70 cases $(93.3 \%)$. There were 2 lines of improvement on Snellen's acuity in $26(49.1 \%)$ of the MSICS-trab and in $12(54.5 \%)$ of the phaco-trab cases.

The vision improvement achieved was not statistically different in the two types of combined cases $(p>0.05)$. There were five cases of transient hypotony without maculopathy in which IOP stabilized without any intervention

There were no complications in $83.1 \%$ of the MSICS-trab and $86.4 \%$ of the phaco-trab group showing statistically insignificant difference. Complications were transient hypotoney in 3 cases(5.6\%)in MSICS group and 1case (4.4\%) in phacotrabeculectomy group. Descemet's detachment reported in 2 cases $(3.7 \%)$ in small incision group and not reported in phacotrabeculectomy group. Hyphema reported in 1 case (1.8\%) in MSICS group and not 
reported in phacotrabeculectomy group. In our study no any case showed postoperative hypotony, hyphema or descemet detachment ${ }^{(\mathbf{1 5})}$.

Venkataraman et al. (15) published the following study in glaucoma session in congress of ESCRS 2017. The aim of the study is to assess the changes in the intraocular pressure, endothelial cell density, visual acuity and refractive changes (induced astigmatism), and per-operative complications in patients undergoing Phaco-TRAB (Group 1) and SICS-TRAB (Group 2) for coexisting primary open angle (POAG)/ angle closure glaucoma (PACG) and cataract

Sixty eyes of 60 patients undergoing either phaco-trab or small incision cataract surgery combined with trabeculectomy were included in the study. This was a nonrandomized comparative study the patients chose the type of surgery. Primary outcome were changes in intraocular pressure and endothelial cell (EC) density and secondary outcomes were astigmatic changes after surgery (induced astigmatism) and intraoperative and postoperative complications at 1,3 and 6 months.

Twenty three patients $(82.1 \%$ in group 1 and $88.4 \%$ in group 2) in both groups obtained a good visual outcome of 0 to 0.2 at 6 th month. The mean IOP at 6 months was 13.68 (SD 3.08) $\mathrm{mmHg}$ in Group 1 and 16.0(SD 4.96) $\mathrm{mmHg}$ in Group 2 ( $\mathrm{p}=0.04)$. The mean surgically induced astigmatism was 0.95 (SD .078) D in group 1 and 1.03(SD 0.75) D in group 2 at 6 months $(\mathrm{p}=0.71)$. The mean EC loss was $13.97 \%$ in group 1 and $10.56 \%$ in group 2 and $(\mathrm{p}=0.05)$. Perioperative complications were more in group 2 than Group 1. At the end of 6 months Phacotrabeculectomy offers a better IOP control and visual rehabilitation with fewer complication when compared with MSICS associated with trabeculectomy ${ }^{(15)}$.

\section{CONCLUSIONS}

It could be concluded that there is significant improvement in the BCVA and IOP control after combined procedure for management of coexistent cataract and glaucoma. This improvement is statistically significant. There was no statistically significant difference in the final visual acuity, IOP control and post-operative complication rate between phacotrabeculectomy and small incision trabeculectomy.

\section{REFERENCES}

1. Shahsuvaryan M (2016): The management of cataract: where we are? EC Ophthalmology, 3.3:304.
2. Gupta VB, Manjusha R (2014): Etiopathogenesis of cataract: an appraisal. Indian Journal of Ophthalmology, 62:103 -110.

3. American Academy of Ophthalmology (2014): What is glaucoma. http;//www.nei. nih.gov//health/glaucoma.

4. World Glaucoma Association (2017): What Is Glaucoma?. www.world glaucoma.org

5. Bharati S, Sethi $H$ and Chaturvedi $N(2008)$ : Glaucoma practice. Journal of Current Glaucoma Practice, 2(3): 33-47.

6. Murthy SK, Damji KF, Pan Y et al. (2006): Trabeculectomy and phacotrabeculectomy, with mitomycin-C, show similar two-year target IOP outcomes. Can J Ophthalmol., 41(1):51-59.

7. Khurana AK, Chawla U, Passi N et al. (2011): combined SICE andtrabeculectomy. Nepal Journal Of Ophthalmology, 3 (5) :13-18.

8. Hoffman KB, Feldman RM Budenz DL et al. (2002): Combined cataract extraction and baerveldt glaucoma drainage implant. Ophthalmology, 109:1916-20.

9. Donoso R, Rodrfguez A (2000): Combined versus sequential phacotrabeculectomy with intraoperative 5-fluoracil. J Cataract Refract Surg., 26:71-77.

10. Liaska A, Papaconstantinou D, Georgalas I et al. (2014): Phaco-trabeculectomy in controlled, advanced, open-angle glaucoma and cataract: Parallel, randomized clinical study of efficacy and safety. Semin Ophthalmol., 29:226-35.

11. Husain R (2014): The management of patients with cataracts and medically uncontrolled glaucoma. Med Hypothesis Discov Innov Ophthalmol., 3:2030.

12. Singh K, Mutreja A and Jain $P$ (2015): A comparative evaluation of phacotrabeculectomy with manual phacofracture trabeculectomy. MAMC J Med Sci., 1:6-11

13. Choy BNK (2017): Comparison of surgical outcome of trabeculectomy and phacotrabeculectomy in Chinese glaucoma patients. Int J Ophthalmol., 10(12):1928-1930.

14. Khandelwal RR, Raje D, Rathi A et al. (2015): Surgical management of cataract coexistent with glaucoma. Eye, 29: 363-370

15. Venkataraman G, Dhavalikar $M$ and Chandran P (2017): Comparative study of phacotrabeculectomy (Phaco-Trab) and manual small incision cataract and trabeculectomy (SICSTrab) in primary glaucoma. Glaucoma Session ESCRS LISBON 2017. https://issuu.com/eurotimes/docs/escrslisbon2017_ final_programme_pre 